\title{
Coagulopathy associated with COVID-19 - Perspectives \& Preventive strategies using a biological response modifier Glucan
}

\author{
Nobunao Ikewaki ${ }^{1,2}$, Kosagi-Sharaf Rao ${ }^{3}$, Armando Durant Archibold ${ }^{3}$, Masaru Iwasaki $^{4}$, Rajappa Senthilkumar ${ }^{5}$,
} Senthilkumar Preethy ${ }^{5}$, Shojiro Katoh ${ }^{6}$ and Samuel J. K. Abraham ${ }^{4,6,7,8^{*}}$ (D)

\begin{abstract}
Direct endothelial injury by viruses and dysregulation of clotting mechanisms due to cytokine storm are the major precipitating factors of mortality in COVID-19; both are attributed to a fundamental dysregulation of the immune system. While immune dysregulation can be attributed to several factors, the risk of associated thrombogenic disruption varies across individuals. This variation depends on several factors, such as comorbidities, including diabetes, hypertension, and cardiovascular diseases. When considering ethnic variations, the vulnerability of Caucasians, African Americans and Hispanics needs to be addressed before arriving at strategies to handle thromboembolic complications, which have been identified in recent reports as the leading causes of mortality in COVID-19. Although evaluation of D-dimer and prothrombin during admission is considered to predict prognosis and mortality, there are no preventive or prophylactic strategies before hospital admission. Herein, we present our perspectives on the effect of regular supplementation with the biological response modifier beta glucan based on its relevance to immune modulation. This effect is of paramount importance in decreasing the development of severe COVID-19 and reducing mortality against the background of coagulopathy, especially in vulnerable populations.
\end{abstract}

\section{Introduction}

Severe acute respiratory syndrome coronavirus 2 (SARS-CoV-2), the novel virus behind the coronavirus disease (COVID-19) pandemic, is wreaking havoc around the world [1]. Efforts are ongoing to understand the pathophysiological processes underlying the disease to mitigate complications. While severe acute respiratory distress syndrome is the major cause of death, other organ failures, such as acute kidney failure and acute cardiac injury, have also been associated with the disease [1].

\footnotetext{
* Correspondence: drsam@nichimail.jp

${ }^{4}$ II Department of Surgery \& Centre for Advancing Clinical Research (CACR), Yamanashi University- School of Medicine, Chuo, Japan

${ }^{6}$ Edogawa Evolutionary Laboratory of Science (EELS), Edogawa Hospital, Tokyo, Japan

Full list of author information is available at the end of the article
}

The inflammatory response is highly increased during COVID-19 infection, and this process sets the stage for organ failure. Elevation of Th1 cytokine interferon (IFN)-gamma; inflammatory cytokines interleukin (IL)-1, IL-6, and IL-12; neutrophil chemokine IL-8; monocyte chemoattractant protein-1 (MCP-1); and Th1 chemokine IFN-gamma-inducible protein-1 [2] leads to a cytokine storm (CS) called macrophage activation syndrome (MAS) or secondary haemophagocytic lymphohistiocytosis (sHLH), which causes tissue damage [3]. Other immune dysregulation-related phenomena, including complement activation, also play a role in the organ failure caused by the virus. The host's innate and adaptive immunity must come into play, encompassing different aspects, including the production of various proinflammatory cytokines and the activation of CD4 and

(c) The Author(s). 2020 Open Access This article is licensed under a Creative Commons Attribution 4.0 International License, which permits use, sharing, adaptation, distribution and reproduction in any medium or format, as long as you give appropriate credit to the original author(s) and the source, provide a link to the Creative Commons licence, and indicate if changes were made. The images or other third party material in this article are included in the article's Creative Commons licence, unless indicated otherwise in a credit line to the material. If material is not included in the article's Creative Commons licence and your intended use is not permitted by statutory regulation or exceeds the permitted use, you will need to obtain permission directly from the copyright holder. To view a copy of this licence, visit http://creativecommons.org/licenses/by/4.0/ The Creative Commons Public Domain Dedication waiver (http://creativecommons.org/publicdomain/zero/1.0/) applies to the data made available in this article, unless otherwise stated in a credit line to the data. 
CD8+ $\mathrm{T}$ cells for controlling viral infection and downregulating inflammation [3].

Coagulopathy has been reported in patients with SARS-CoV-2. Coagulation changes in patients with COVID-19 have been reported to include both disseminated intravascular coagulopathy (DIC) and sepsis-induced coagulopathy (SIC) [4]. During the early phase of COVID-19 infection, there is no clinical bleeding despite coagulation test abnormalities. Several factors, including certain treatments, have been found to culminate in the later development of SIC or DIC. The term COVID-19-associated coagulopathy (CAC) has been used to describe the coagulation changes occurring in COVID-19 patients [4]. Coagulopathy leading to venous thromboembolic events, end-organ failure secondary to a microangiopathy similar to disseminated intravascular coagulation (DIC), and stroke have all been reported in COVID-19 but with distinct features, wherein this coagulopathy in COVID-19 is associated with an increased risk of death [5]. However, it should be noted that even in the absence of advanced COVID19, large artery stroke has been reported [6]. ACE2 receptors are expressed widely within endothelial cells, which could explain their vulnerability to SARS-CoV-2 binding, membrane fusion, and viral entry, thereby leading to infection and direct vascular injury [7] and giving rise to the coagulopathyassociated sequence in COVID-19.

Comorbidities such as diabetes, hypertension [8], and cardiovascular diseases [9] have been associated with a higher risk of complications and mortality due to COVID-19 [10]. Pre-existing increased plasmin activity occurring in hypertension, diabetes, and cardiovascular disease enhances the virulence and infectivity of the SARS-CoV-2 virus by cleaving its spike proteins, which in turn aggravates this coagulationrelated process [11].

Herein, we report our perspectives on how people predisposed to coagulopathy and thrombogenic events could be the main target at high risk of complications due to COVID-19, and preventive measures can possibly be undertaken to allow predisposed people to successfully defend against complications due to COVID-19.

\section{Coagulopathy and COVID-19 - pathological mechanisms}

In COVID-19, two separate pathologic processes have been found to play a role in producing clinical manifestations of coagulopathy: (i) local direct vascular and endothelial injury by invasion of the virus producing microvascular clot formation and angiopathy and (ii) mononuclear and polymorphonuclear infiltration along with apoptosis of endothelial and mononuclear cells as consequence of inflammation. Hypercoagulability with hyperfibrinogenaemia causing large vessel thrombosis and major thromboembolic sequelae should also be considered. The most common and critical feature observed in patients with coagulopathy-related predisposition to COVID-19 is abnormally elevated D-dimer levels. Elevated D-dimer levels have been associated with a poor prognosis. Increased prothrombin times (PTs) and activated partial thromboplastin times (aPTTs), lower platelet counts, and increased levels of lactate dehydrogenase (LDH) and ferritin are other factors associated with a poor prognosis in several studies [10].

A review article that provides guidance for the haemostasis laboratory in the management of the thrombotic risk associated with COVID-19 [12] suggests that the most seriously affected individuals have slightly longer PT than patients with more favourable prognosis. APTT is generally proportionally less prolonged than PT, probably due to an increase in plasma concentration of factor VIII and a low platelet count at admission (i.e., $<200 \times$ $109 / \mathrm{L}$ ), but it has also been associated with increased risk of death. The authors recommend monitoring the plasma concentration of PT, fibrinogen, D-dimers and platelet count every $48 \mathrm{~h}$ to continuously assess the thrombotic risk and identify timely warning signs of possible venous thrombotic events [12].

Hardy et al. [13] suggest that studies reporting on haemostasis in COVID-19 should ensure the careful reporting of laboratory methods to enable a correct interpretation of the thrombo-embolic risk and effects in COVID-19. For instance, a high variability in heparin plasma level measurement between the available measurement kits has been reported. The authors mention that the reagents designed to measure thrombin potentials require standardization. Some patients exhibit heparin resistance, which may be due to the normal thrombin generation profiles, which would have been reported as abnormal levels due to the methodologies employed. They also question whether viscoelastometric tests (VETs) recommended for studying thrombogenic profiles are truly standardized on a global scale [13].

Iba et al. [11] describe the four pathways of coagulation-related events and thrombus formation in COVID-19: (i) CS and pro-inflammatory cytokines such as interleukin (IL)-1 $\beta$ and IL-6 stimulate the expression of tissue factor on immune cells, thereby initiating extrinsic coagulation cascade activation; (ii) suppression of the fibrinolytic system by the decreased activity of urokinase-type plasminogen activator and increased release of plasminogen activator inhibitor-1; (iii) activation of platelets by various pro-inflammatory cytokines and the damaged endothelium readily binding with the activated platelets; and (iv) direct endothelial damage induced by inflammation. 


\section{Coagulopathy and COVID-19 - incidence and vulnerable populations}

Because the thrombogenesis associated with COVID-19 is complex and very little understood, a potential distinct "COVID-19-induced coagulopathy pattern" has been postulated [14]. The first report of haemostasis disorders in patients with COVID-19 was by Guan et al. on 28 February 2020 [15]. In this initial cohort of 1099 hospitalized patients with COVID-19, an increased D-dimer level above $0.5 \mathrm{mg} / \mathrm{L}$ was seen in $46.4 \%$ of the patients during initial presentation $[15,16]$. In 191 hospitalized patients with COVID-19, 81\% of non-survivors had Ddimer levels greater than $1 \mathrm{mg} / \mathrm{L}$ on admission [17]. A higher D-dimer level was identified in $59.6 \%$ of severe infections compared to $43.2 \%$ of non-severe COVID-19 patients. In fact, DIC has emerged as a strong predictor of mortality, with $71.4 \%$ of non-survivors meeting the criteria for DIC compared to only $0.6 \%$ of survivors [18]. Therefore, regular monitoring of D-dimer, prothrombin, and fibrinogen in COVID-19 is recommended because a significant increase in D-dimer and prothrombin with a decrease in fibrinogen has been observed at days 10-14 in non-survivors, and an elevated D-dimer level (above 1 $\mathrm{mcg} / \mathrm{mL}$ ) has been reported to be a strong independent risk factor in this vulnerable population $[16,19]$. Caution should be exercised when interpreting plasma D-dimer values and unfavourable prognosis in COVID-19 because different thresholds have been proposed for stratifying the risk of mortality (i.e., between 1000 and 3000 $\mathrm{ng} / \mathrm{mL}$ ), and in the presence of significant pulmonary inflammation, fibrin deposits can occur within alveoli and the pulmonary extravascular space, whose lysis may also contribute to the rise of D-dimers [13]. Nevertheless, the working group on perioperative haemostasis considers patients with plasma D-dimer levels $>3000 \mathrm{ng} / \mathrm{mL}$ as having a very high thromboembolic risk; these patients might benefit from increased doses of heparin, and continued thromboprophylaxis is recommended after hospital discharge for a maximum of 45 days [20].

Other reports on the incidence of coagulopathy in COVID-19 include one with 150 patients with COVID-19, among whom 25 (16.7\%) experienced a pulmonary embolism and two had three thrombotic circuit occlusions [21]. Lupus anticoagulants were detected in 50 of 57 patients tested (87.7\%) [22]. Oxley et al. reported five patients with acute large vessel occlusion with ischaemic stroke [23]. In the original cases reported from Wuhan, China, stroke was seen in 5\% of patients [24]. Another report indicated an incidence of thrombotic complications of $16-49 \%$ in patients with COVID-19 admitted to intensive care [13]. With regard to deep-vein thrombosis (DVT), of 143 patients hospitalized with COVID-19, 66 developed lower extremity DVT [25].
Because most of the COVID-19 coagulopathy data are from Chinese patients owing to the first reporting of COVID-19 being from China and because the incidence of venous thromboembolism is approximately 3- to 4fold lower in Chinese patients [26], coagulopathy and thrombo-embolic events have been less important in Chinese hospitals, and the use of thromboprophylaxis is also less common. However, with the disease having affected Caucasian individuals at a magnitude several times greater than it has affected Chinese individuals, it is essential to know the ethnicity-related risk of thrombogenic events. Caucasians have higher thrombotic risk than Chinese and other Asian populations, and the risk is even higher in African-American and Hispanic patients in the USA [27-29]. Consistent with this pattern, a study conducted on COVID-19 coagulopathy in Caucasian patients showed that although the risk of coagulopathy was higher in Caucasians, because the patients included in the study were on low-molecularweight heparin (LMWH) thromboprophylaxis, they rarely developed overt DIC, and in cases where DIC developed, it was during the later stages of the disease only. The study also reported a novel pulmonary-specific vasculopathy, which we term pulmonary intravascular coagulopathy (PIC), associated with COVID-19, that is distinct from DIC [30, 31]. Table 1 presents the racebased risk for COVID-19 coagulopathy, which confirms that the risk of coagulopathy is higher in Caucasians, African-Americans and Hispanics who should be treated with caution when affected with COVID-19 [32-40].

Activation of innate immunity with older age and agerelated coagulation cascade changes are also factors that have been reported to contribute to the vulnerability of elderly people to COVID-19 coagulopathy [41]. Alveolar macrophages (AMs) increase during ageing, but their plasticity to convert between pro- and anti-inflammatory states is greatly reduced. This accelerates COVID-19 in its early stages in the elderly and in advanced stages, causing excessive lung damage. A decline in neutrophil activity during ageing causes these cells to lose their ability to migrate to sites of infection and kill infected cells. The production and diversity of mucins and protective glycoproteins contributing to mucosal barriers also change during ageing [42]. The immunosenescence of the adaptive immune system in the aged also contributes to progression to severe COVID-19 in this population. A decline in the production of fresh naïve T cells, a less expansive $\mathrm{T}$ cell receptor (TCR) repertoire, $\mathrm{T}$ cell metabolic dysfunction, and weaker activation of $\mathrm{T}$ cells also contribute to immune vulnerability of the aged to COVID-19. An exploration of the link between the immune system and coagulopathy in the aged, which makes them a vulnerable population, identified that one in two fatal cases of COVID-19 experience a CS, among 
Table 1 Factors pre-disposing a specific Race/Ethnicity for increased risk of coagulopathy

\begin{tabular}{|c|c|c|c|c|c|c|c|c|}
\hline S.No & Race/Ethnicity & $\begin{array}{l}\text { Factor V Leiden } \\
\text { andprothrombin } \\
\text { gene polymorphism } \\
{[32,33]}\end{array}$ & $\begin{array}{l}\text { Non-O } \\
\text { Blood } \\
\text { Group }[32,34]\end{array}$ & $\begin{array}{l}\text { Lower Protein } \\
\text { C levels } \\
{[32,35,36]}\end{array}$ & $\begin{array}{l}\text { High levels of } \\
\text { Procoagulant } \\
\text { proteins FVIII } \\
\text { andvon Willebrand } \\
\text { factor }[32,37]\end{array}$ & $\begin{array}{l}\text { Elevated } \\
\text { levels of } \\
\text { D-Dimer } \\
{[32,38]}\end{array}$ & $\begin{array}{l}\text { Undergoing } \\
\text { surgery }[32,39]\end{array}$ & $\begin{array}{l}\text { Obesity } \\
{[32,40]}\end{array}$ \\
\hline 1 & $\begin{array}{l}\text { Caucasians/ } \\
\text { Europeans }\end{array}$ & High prevalence & $\begin{array}{l}\text { High } \\
\text { prevalence }\end{array}$ & $\begin{array}{l}\text { High } \\
\text { prevalence }\end{array}$ & & $\begin{array}{l}\text { High } \\
\text { prevalence }\end{array}$ & & \\
\hline 2 & Afro-Americans & $\begin{array}{l}\text { Intermediate } \\
\text { prevalence }\end{array}$ & & & High prevalence & & High prevalence & $\begin{array}{l}\text { High } \\
\text { prevalence }\end{array}$ \\
\hline 3 & Hispanics & & & & & $\begin{array}{l}\text { Intermediate } \\
\text { prevalence }\end{array}$ & & $\begin{array}{l}\text { High } \\
\text { prevalence }\end{array}$ \\
\hline 4 & Africans & & & & & & & \\
\hline 5 & Asians & Low prevalence & & $\begin{array}{l}\text { High prevalence } \\
\text { (Japanese, } \\
\text { Taiwanese } \\
\text { and Thai) }\end{array}$ & & & Low prevalence & \\
\hline
\end{tabular}

whom $82 \%$ are over the age of 60 [43]. Inflammaging is a major driver for this increased CS occurring in aged individuals, exacerbated by obesity, poor diet and oral health, microbial dysbiosis, and sedentary lifestyle [43]. Age-related correlation of higher basal circulating levels of pro-inflammatory cytokines, including IL-6, TNF- $\alpha$, $\mathrm{IL}-1 \alpha$, and CRP, is a reported phenomenon. During ageing, there is a gradual decline in immune function called immunosenescence and a chronic increase in systemic overactive but ineffective inflammation, a process known as inflammaging. Immunosenescence is characterized by impairment of both arms of immunity, innate and adaptive, and is characterized by ineffective pathogen recognition, macrophage activation, a reduction in natural killer (NK) cell cytotoxicity, thymic atrophy and accumulation of anergic memory lymphocytes [41]. The inflammaging process in older patients underlies the rapid progression to cytokine storms, whose key player is NLRP3, which is the major protein component of the inflammasome and is abundant in older individuals. NLRP3 priming induced by TLRs or tumour necrosis factor receptor activation leads to pro-inflammatory cytokine production, and activation is triggered by a range of stimuli that emerge during infections, such as tissue damage, nucleic acids, and invading pathogen proteins [41]. This process is further aggravated by decreased activity of sirtuin 2 (SIRT2) in the aged, as SIRT2 directly controls NLRP3 [41]. This cytokine storm disrupts the feedback control mechanisms of thrombin generation by antithrombin III, a tissue factor pathway inhibitor, and the protein $\mathrm{C}$ system, which predisposes individuals to the development of microthrombosis and DIC [43].

Coagulopathy seems to be the central factor predicting the progression of COVID-19. It also explains why children rarely experience severe illness due to COVID-19, as thrombotic complications in the paediatric age group are rare in the absence of an underlying cancer or a central venous access device. While pregnant women should be expected to have high vulnerability to coagulopathy, they have, in fact, been found to have only milder illness because of immune suppression during the gestational period to avoid foetal rejection, and thus, immunothrombosis does not come into play [43].

The vulnerability of patients with cardiovascular risk factors such as obesity, hypertension, and diabetes to the disease severity of COVID-19 is well established [7-9, 44]. Imbalance between coagulation and fibrinolysis with increased levels of clotting factors and relative inhibition of the fibrinolytic system, endothelial dysfunction, and enhanced platelet aggregation and activation, which are complications of diabetes, favour the development of a hypercoagulable pro-thrombotic state, thus explaining the high risk of diabetes patients to COVID-19 in terms of disease severity [44]. With regard to hypertension, other cardiovascular diseases, in addition to alterations in vascular and thrombogenic factors, pulmonary and peripheral endothelial injury due to direct viral attack, and CS have been indicated as inducers of hypercoagulation in these patients [45]. Another factor of concern is microparticles (MPs) [14]. These MPs are shed due to cell blebbing induced by activation of circulating blood cells, including platelets and leukocytes, and of endothelial cells by the COVID-19-induced cytokine storm. The membrane proteins on these MPs carry proteins and miRNAs to transmit the activator signal to distant cells propagating the disease and promote pro-coagulant responses due to the exposure of tissue factors and the activation of the coagulation cascade, ultimately leading to thrombin generation. Elevated levels of procoagulant MPs have been described in conditions such as arterial hypertension, diabetes mellitus, dyslipidaemia, obesity, pulmonary embolism, arterial hypertension, acute coronary syndromes, heart failure, etc. Thus, these individuals 
are at high risk of COVID-19-associated coagulopathy [14]. In the case of cardiovascular comorbidities, it has been hypothesized that damage mediated by the release of inflammation mediators acts on the vascular endothelium, leading to hypercoagulability and hypoxic damage by alterations of perfusion (acute coronary syndrome, thromboembolism, DIC) [46]. The immune response is also responsible for myocarditis with myocardial damage. Imbalance of the normal circulatory and inflammatory homeostasis due to alterations in the ACE2 receptor adds to the pathogenetic mechanisms of the damage, which is exacerbated by certain drugs used in people with hypertension, diabetes, and vascular disease, thus making these individuals at high risk of cardiovascular and thrombogenic events [46].

\section{Preventive and therapeutic aspects of coagulopathy in COVID-19}

Having identified the various populations vulnerable to coagulopathy-associated severity of COVID-19, we now turn towards possible therapeutic solutions and preventive strategies. Recent guidelines recommend thromboprophylaxis for all hospitalized COVID-19 patients or full therapeutic-intensity anticoagulation [47]. Antiplatelet drugs, thrombolysis, immunomodulatory agents, and anti-complement drugs are suggested approaches. For anticoagulation, the drug of choice is low molecular weight heparin, and in patients who might have severe renal impairment or extremely high risk of bleeding, unfractionated heparin is recommended [48]. Preventive aspects deal with treating the comorbidities and end with a maximum level of thromboprophylaxis, but all of these measures are suggested after a patient is hospitalized. We explored whether any other preventive strategy is available. Supplementation with the biological response modifier beta glucan (BRMG) could be a solution in the vulnerable population. Beta glucans are potent biological response modifiers.

The effects of BRMG in infections and septic shock have been reported in both in vivo animal models and clinical studies [49]. BRMGs such as the soluble beta 1,3 glucans have been found to decrease septic complications and improve survival by acting on cytokine production and regulating coagulation activation [50] in a rat model. Preventive supplementation by BRMG prior to infection with $S$. aureus prevented sepsis in a guinea pig model [49]. Macrophage activation by BRMG has been shown to significantly reduce septic morbidity and mortality in human patients $[51,52]$. In a randomized phase I/II trial, BRMG supplementation as an immune prophylaxis helped reduce postoperative infectious complications in patients undergoing major surgery by stimulating leucocytosis and phagocytic activity [52]. BRMG recognizes and interacts with the innate immune system in humans to help combat infections [53]. Radiation exposure and/or diabetes-induced oxidative stress, which causes disturbances in the measured clotting parameters by enhancing platelet aggregation and increasing thrombin levels, were reversed by yeast BRMG [50].

A BRMG from a black yeast, Aureobasidium pullulans (AFO-202), has been reported to be a potent immune modulator acting through its receptor, Dectin-1, which cooperates with pattern recognition receptors (PRRs) and Toll-like receptors (TLRs) in the innate immune response [54]. This BRMG reduces the levels of IL-1 $\beta$, IL-2, IL-4, IL-6, IL-12, TNF- $\alpha$, IFN- $\gamma$, and sFasL while increasing IL8 and sFAS [34], thereby balancing an effective optimal defence against viral infection without hyperinflammation. Anti-viral defence activities of BRMG occur through increased IL8, which causes activation, migration, and chemotaxis of neutrophils to kill virusinfected cells; increased type-I IFN production, which helps kill virus-infected cells; increased IL-7 production, which leads to development and survival of mature T-cells to maintain homeostasis; activation of B-cells, which results in production of virusspecific antibodies (IgG, IgM and sIgA) for neutralization of virus toxicity; and increased NK cell activity and macrophage activity [7]. Prevention of hyperinflammation occurs by preventing the onset of apoptosis through increased sFAS production, regulation and suppression of CS through activation of Treg cells and decreased IL6, and prevention of chemoattraction of monocytes and macrophages, $\mathrm{T}$ cells, NK cells, and dendritic cells through a decrease in CXCL10 and CCL2 (monocyte chemotactic protein 1; MCP-1) [7]. AFO-202 BRMG was found to enhance NK activity and cellular immunity in Leishmania amazonensis-infected mice [55]. AFO-202 BRMG has been demonstrated to protect mice infected with a lethal titre of the A/Puerto Rico/8/34 (PR8; H1N1) strain of influenza virus, and the mechanism of action was found to be through inhibition of viral replication [56].

The effects of this BRMG in acting as a prophylactic supplement to help combat coagulopathy associated with COVID-19 are illustrated in Fig. 1.

SARS-CoV-2 infection triggers a cascade of events that result in a gradually increasing hyperinflammatory state, which in turn provokes thrombogenicity culminating in a potentially devastating microangiopathy, contributing to COVID-19-induced acute respiratory distress syndrome (ARDS) and organ damage [57]. AFO-202 BRMG has been proven to attenuate CS caused by proinflammatory cytokines such as IL-6 while mounting anti-viral defence [54] by upregulating NK cells, macrophages and factors such as IL8, sFAS, type I IFN, IL and 


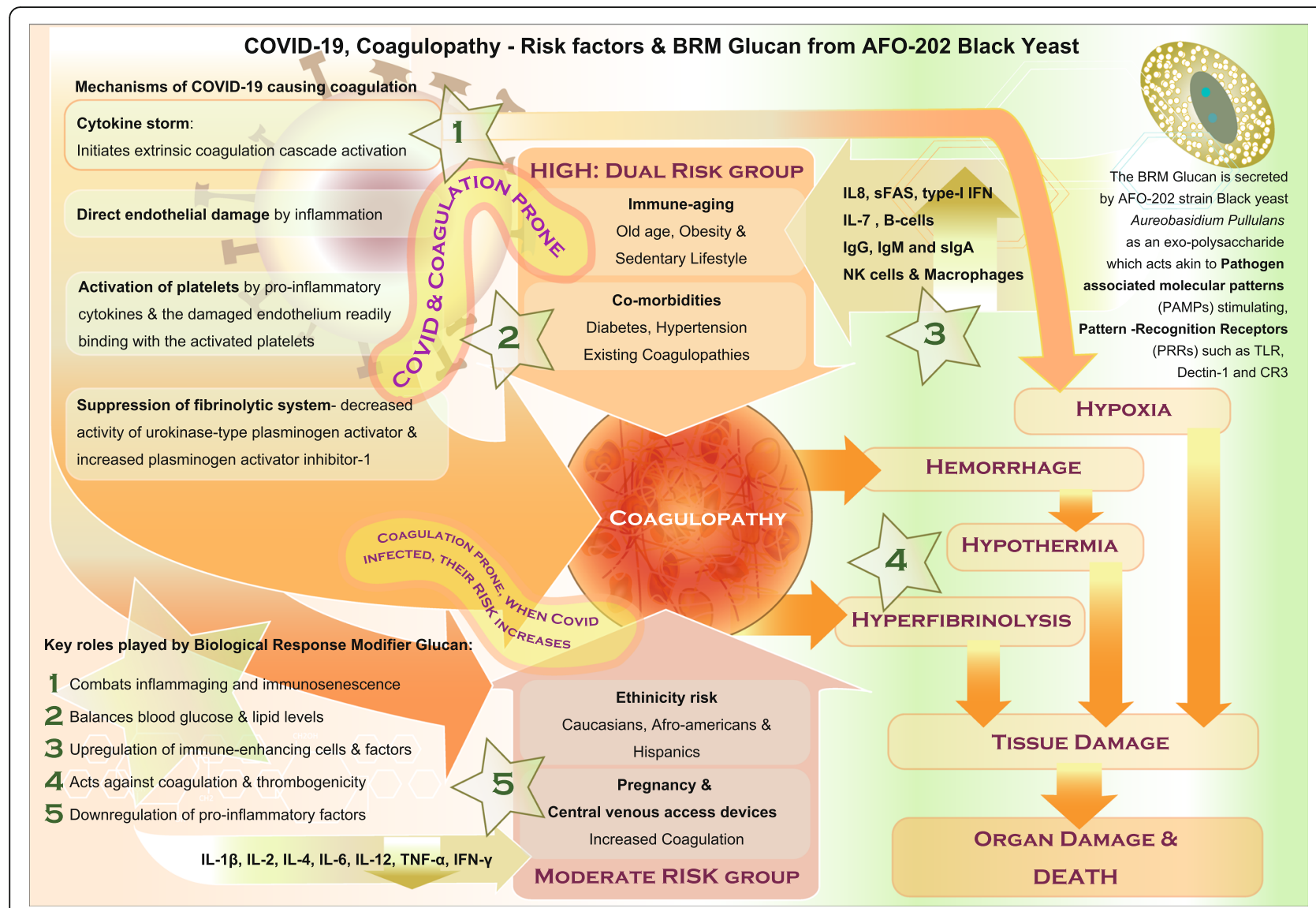

Fig. 1 A schematic illustration of the implications of the COVID-19 coagulopathy cascade and the stepwise mechanism that leads to organ damage. Various risk factors modulated by the biological response modifier (BRM) glucan at various steps of this cascade are listed and graded

antibodies. AFO-202 BRMG has also been proven efficacious in lifestyle diseases in East Asian and South Asian populations with maintenance of blood glucose and lipid levels [58-60]. Since comorbidities such as hypertension, diabetes mellitus, dyslipidaemia and obesity have a very strong correlation to coagulopathies due to the presence of a dysregulated inflammatory system [61], BRMG will be beneficial in decreasing the risk of coagulopathy in these individuals with dual risk (COVID-19-induced risk and comorbidity-induced risk). BRMGs have been reported to have direct antiplatelet, antioxidative, anticoagulant and antithrombotic actions, which further supports their beneficial effects as a supplement to prevent COVID-19-associated coagulopathy. Due to these attributes of BRMG, although it has not been tested in people with COVID-19 or those with ethnic or other predispositions to coagulopathy, it is worth considering its efficacy in controlling a pathophysiology that may trigger coagulopathy due to hyperinflammation.

\section{Conclusion}

The proposed mechanisms for multiorgan dysfunction in COVID-19 are multifactorial, and a hypercoagulable state with micro- and macrocirculatory thrombosis has been identified as a key factor determining the clinical course and disease severity. Ethnically vulnerable populations such as Caucasians, African Americans, Hispanics, the elderly population, and patients with comorbidities are at high risk and require prevention during this hypercoagulable state. D-dimer and prothrombin have emerged as the most important biomarkers to be analysed at the time of hospital admission due to COVID-19. In the present scenario, where there is no definite pharmacological remedy for prevention or treatment presently available, a biological response modifier beta glucan food supplement that has several advantages in modulating the immune response is considered to be worth recommendation for clinical studies of COVID-19, especially in vulnerable populations.

\section{Acknowledgements}

We thank Mr. Takashi Onaka, (Sophy Inc., Kochi, Japan), for necessary technical clarifications. KR \& AD are thankful to National Science System (SNI62-2019) of SENACYT, Panama for the support. RS \& SP are thankful to Loyola-ICAM College of Engineering \& Technology (LICET), Loyola Campus, Chennai, India for their support. 


\section{Authors' contributions}

$\mathrm{NI}, \mathrm{KR}$, SK, and SA contributed to conception and design of the study. RS performed the literature search and data analysis. SA \& SP drafted the manuscript. AD, MI, KR \& SA performed critical revision of the manuscript. All the authors read, and approved the submitted version.

\section{Funding}

The article did not receive any external funding.

\section{Availability of data and materials \\ Not applicable.}

\section{Ethics approval and consent to participate}

Not applicable.

\section{Consent for publication}

Not applicable.

\section{Competing interests}

1. Nobunao Ikewaki is an employee of Dept. of Medical Life Science, Kyushu University of Health and Welfare, Japan \& Institute of Immunology, Junsei Educational Institute, Nobeoka, Miyazaki, Japan

2. Rao Kosagi-Sharaf and Armando Durant Archibold are employees of INDI CASAT AIP, Panama

3. Masaru Iwasaki is a faculty in Yamanashi University, Japan 4. Rajappa Senthilkumar and Senthilkumar Preethy are employees of NCRM, India

5. Shojiro Katoh is a faculty of EELS \& employee of Edogawa Hospital, Japan 6. Samuel Abraham is a faculty in Yamanashi University, EELS, Edogawa Hospital, Japan \& NCRM, India, as well as shareholder in GN Corporation, Japan which in turn is a shareholder in the manufacturing company of the AFO 202 Beta Glucan.

\section{Author details}

'Department of Medical Life Science, Kyushu University of Health and Welfare, Nobeoka, Miyazaki, Japan. ${ }^{2}$ Institute of Immunology, Junsei Educational Institute, Nobeoka, Miyazaki, Japan. Instituto de Investigaciones Científicas y Servicios de Alta Tecnología (INDICASAT AIP), City of Knowledge, Panama City, Panama. ${ }^{4} \|$ Department of Surgery \& Centre for Advancing Clinical Research (CACR), Yamanashi University- School of Medicine, Chuo, Japan. ${ }^{5}$ The Fujio-Eiji Academic Terrain (FEAT), Nichi-In Centre for Regenerative Medicine (NCRM), Chennai, India. ${ }^{6}$ Edogawa Evolutionary Laboratory of Science (EELS), Edogawa Hospital, Tokyo, Japan. ${ }^{7}$ The Mary-Yoshio Translational Hexagon (MYTH), Nichi-In Centre for Regenerative Medicine (NCRM), Chennai, India. ${ }^{8}$ GN Corporation Co. Ltd, Kofu, Japan.

Received: 22 July 2020 Accepted: 22 September 2020

Published online: 16 October 2020

\section{References}

1. Nahum J, Morichau-Beauchant T, Daviaud F, Echegut P, Fichet J, Maillet JM, Thierry S. Venous thrombosis among critically ill patients with coronavirus disease 2019 (COVID-19). JAMA Netw Open. 2020;3:e2010478.

2. Quartuccio L, Semerano L, Benucci M, Boissier MC, De Vita S. Urgent avenues in the treatment of COVID-19: targeting downstream inflammation to prevent catastrophic syndrome. Joint Bone Spine. 2020;87:191-3.

3. Tufan A, Avanoğlu Güler A, Matucci-Cerinic M. COVID-19, immune system response, hyperinflammation and repurposing antirheumatic drugs. Turk J Med Sci. 2020:50:620-32

4. Connors JM, Levy JH. COVID-19 and its implications for thrombosis and anticoagulation. Blood. 2020;135:2033-40.

5. Levi M, Thachil J, Iba T, Levy JH. Coagulation abnormalities and thrombosis in patients with COVID-19. Lancet Haematol. 2020;7:e438-40.

6. Fara MG, Stein LK, Skliut M, Morgello S, Fifi JT, Dhamoon MS. Macrothrombosis and stroke in patients with mild Covid-19 infection. J Thromb Haemost. 2020. https://doi.org/10.1111/jth.14938.

7. Rao KS, Suryaprakash V, Senthilkumar R, Preethy S, Katoh S, Ikewaki N, Abraham S. Role of immune dysregulation in increased mortality among a specific subset of COVID- 19 patients and immune-enhancement strategies for combatting through nutritional supplements. Front Immunol. 2020. https://doi.org/10.3389/fimmu.2020.01548.
8. Fang L, Karakiulakis $\mathrm{G}$, Roth M. Are patients with hypertension and diabetes mellitus at increased risk for COVID-19 infection? Lancet Respir Med. 2020;8: e21.

9. Wang $B, L i R, L u Z$, Huang $Y$. Does comorbidity increase the risk of patients with COVID-19: evidence from meta-analysis. Aging (Albany NY). 2020;12: 6049-57.

10. Monteil V, Kwon H, Prado P, et al. Inhibition of SARS-CoV-2 Infections in Engineered Human Tissues Using Clinical-Grade Soluble Human ACE2. Cell. 2020;181:905-913.e7.

11. Iba T, Levy JH, Levi M, Connors JM, Thachil J. Coagulopathy of coronavirus disease 2019. Crit Care Med. 2020. https://doi.org/10.1097/CCM. 0000000000004458

12. Hardy M, Douxfils J, Bareille M, et al. Studies on hemostasis in COVID-19 deserve careful reporting of the laboratory methods, their significance and their limitations [published online ahead of print, 2020 Aug 13]. J Thromb Haemost. 2020;https://doi.org/10.1111/jth.15061.

13. Hardy M, Lecompte T, Douxfils J, et al. Management of the thrombotic risk associated with COVID-19: guidance for the hemostasis laboratory. Thrombosis J. 2020;18:17. https://doi.org/10.1186/s12959-020-00230-1.

14. Marchandot B, Sattler L, Jesel L, et al. COVID-19 related coagulopathy: a distinct entity? J Clin Med. 2020;9:E1651.

15. Guan WJ, Ni ZY, Hu Y, et al. Clinical characteristics of coronavirus disease 2019 in China. N Engl J Med. 2020;382:1708-20.

16. Tang N, Li D, Wang X, Sun Z. Abnormal coagulation parameters are associated with poor prognosis in patients with novel coronavirus pneumonia. J Thromb Haemost. 2020. https://doi.org/10.1111/jth.14768.

17. Zhou F, Yu T, Du R, et al. Clinical course and risk factors for mortality of adult inpatients with COVID19 in Wuhan, China: a retrospective cohort study. Lancet. 2020;395:1054-62. https://doi.org/10.1016/S01406736(20)30566-3.

18. Lillicrap D. Disseminated intravascular coagulation in patients with 2019nCoV pneumonia. J Thromb Haemost. 2020;18:786-7. https://doi.org/10. 1111/jth.14781.

19. Becker RC. COVID-19 update: Covid-19-associated coagulopathy [published online ahead of print, 2020 May 15]. J Thromb Thrombolysis. 2020:1-14. https://doi.org/10.1007/s11239-020-02134-3.

20. Susen S, Tacquard CA, Godon A, Mansour A, Garrigue D, Nguyen P, et al. Prevention of thrombotic risk in hospitalized patients with COVID19 and hemostasis monitoring: proposals from the French working group on perioperative Haemostasis (GIHP) the French Sdy group on thrombosis and Haemostasis (GFHT), in collaboration with the French Society for Anaesthesia and Intensive Care (SFAR). Crit Care. 2020;24(1):364.

21. Klok FA, Kruip MJHA, van der Meer NJM, et al. Incidence of thrombotic complications in critically ill ICU patients with COVID-19. Thromb Res. 2020; 191:145-7.

22. Leonard-Lorant I, Delabranche X, Severac F, et al. Acute pulmonary embolism in COVID-19 patients on CT angiography and relationship to Ddimer levels. Radiology. 2020;201561. https://doi.org/10.1148/radiol. 2020201561.

23. Oxley TJ, Mocco J, Majidi S, et al. Large-vessel stroke as a presenting feature of Covid-19 in the young. N Engl J Med. 2020;382(20):e60. https://doi.org/ 10.1056/NEJMc2009787.

24. Zhang $L$, Feng $X$, Zhang $D$, et al. Deep vein thrombosis in hospitalized patients with coronavirus disease 2019 (COVID-19) in Wuhan, China: prevalence, risk factors, and outcome. Circulation. 2020. https://doi.org/10. 1161/CIRCULATIONAHA.120.046702.

25. COVID-19 coagulopathy: an evolving story. Lancet Haematol. Editorial. 2020: 7. https://doi.org/10.1016/S2352-3026(20)30151-4.

26. Huang C, Wang Y, Li X, et al. Clinical features of patients infected with 2019 novel coronavirus in Wuhan, China. Lancet. 2020;395:497-506.

27. Liao S, Woulfe T, Hyder S, Merriman E, Simpson D, Chunilal S. Incidence of venous thromboembolism in different ethnic groups: a regional direct comparison study. J Thromb Haemost. 2014;12:214-9.

28. White RH, Keenan CR. Effects of race and ethnicity on the incidence of venous thromboembolism. Thromb Res. 2009;123(Suppl 4):S11-7.

29. Gurumurthy G, Gaddam A, Patel V, Patel RS. Coaqulopathy and hospital outcomes in patients with spontaneous bacterial peritonitis: a call for action to improve Care of Inpatients. Cureus. 2020;12(6):e8926.

30. Fogarty H, Townsend L, Ni Cheallaigh C, et al. More on COVID-19 coagulopathy in Caucasian patients. Br J Haematol. 2020. https://doi.org/10. 1111/bjh.16791. 
31. McGonagle D, O'Donnell JS, Sharif K, Emery P, Bridgewood C. Immune mechanisms of pulmonary intravascular coagulopathy in COVID-19 pneumonia. Lancet Rheumatol. 2020. https://doi.org/10.1016/S26659913(20)30121-1.

32. Zakai NA, McClure LA. Racial differences in venous thromboembolism. J Thromb Haemost. 2011;9:1877-82. https://doi.org/10.1111/j.1538-7836.2011. 04443.x.

33. Margaglione $\mathrm{M}$, Grandone E. Population genetics of venous thromboembolism. A narrative review. Thromb Haemost. 2011;105:221-31.

34. Folsom AR, Wu KK, Conlan MG, Finch A, Davis CE, Marcucci G, Sorlie PD, Szklo M. Distributions of hemostatic variables in blacks and whites: population reference values from the atherosclerosis risk in communities (ARIC) study. Ethn Dis. 1992;2:35-46.

35. Cushman M. Epidemiology and risk factors for venous thrombosis. Semin Hematol. 2007:44:62-9.

36. Angchaisuksiri P, Atichartakarn V, Aryurachai K, Archararit N, Rachakom B, Atamasirikul K, Tiraganjana A. Risk factors of venous thromboembolism in thai patients. Int J Hematol. 2007;86:397-402.

37. Lutsey PL, Cushman M, Steffen LM, Green D, Barr RG, Herrington D, Ouyang $P$, Folsom AR. Plasma hemostatic factors and endothelial markers in four racial/ethnic groups: the MESA study. J Thromb Haemost. 2006:4:2629-35.

38. Cushman M, Folsom AR, Wang L, Aleksic N, Rosamond WD, Tracy RP, Heckbert SR. Fibrin fragment D-dimer and the risk of future venous thrombosis. Blood. 2003;101:1243-8 10.1182/blood-2002-05-1416 2002-051416.

39. White $\mathrm{RH}$, Zhou $\mathrm{H}$, Romano PS. Incidence of symptomatic venous thromboembolism after different elective or urgent surgical procedures. Thromb Haemost. 2003;90:446-55.

40. Centers for Disease Control and Prevention. Differences in prevalence of obesity among black, white, and Hispanic adults - United States, 20062008. MMWR Morb Mortal Wkly Rep. 2009;58:740-4.

41. Mueller AL, McNamara MS, Sinclair DA. Why does COVID-19 disproportionately affect older people? Aging (Albany NY). 2020;12(10): 9959-81.

42. Jose RJ, Manuel A. COVID-19 cytokine storm: the interplay between inflammation and coagulation. Lancet Respir Med. 2020;8:e46-7.

43. Thachil J, Agarwal S. Understanding the COVID-19 coagulopathy spectrum. Anaesthesia. 2020. https://doi.org/10.1111/anae.15141.

44. Hussain A, Bhowmik B. Do Vale Moreira NC. COVID-19 and diabetes: knowledge in progress. Diabetes Res Clin Pract. 2020;162:108142.

45. Cao W, Li T. COVID-19: towards understanding of pathogenesis. Cell Res. 2020:30:367-9.

46. Mansueto G, Niola M, Napoli C. Can COVID 2019 induce a specific cardiovascular damage or it exacerbates pre-existing cardiovascular diseases? Pathol Res Pract. 2020;216:153086.

47. Kollias A, Kyriakoulis KG, Dimakakos E, Poulakou G, Stergiou GS, Syrigos K. Thromboembolic risk and anticoagulant therapy in COVID-19 patients: emerging evidence and call for action. Br J Haematol. 2020;189:846-7.

48. Engstad CS, Engstad RE, Olsen JO, Osterud B. The effect of soluble beta-1,3glucan and lipopolysaccharide on cytokine production and coagulation activation in whole blood. Int Immunopharmacol. 2002;2:1585-97. https:// doi.org/10.1016/s1567-5769(02)00134-0.

49. Kernodle DS, Gates H, Kaiser AB. Prophylactic anti-infective activity of poly[1-6]-beta-D-glucopyranosyl-[1-3]-beta-D-glucopryanose glucan in a Guinea pig model of staphylococcal wound infection: antimicrobial agents and chemotherapy. Antimicrob Agents Chemother. 1998;42:545-9.

50. El-Kashoury, Fattah SM, Ramadan L, El-Denshary ES. The Role of Yeast Beta Glucan on Blood Coagulation in Streptozotocin-Induced Diabetes and Irradiated Rats. 2016. Available from https://www.semanticscholar.org/ paper/The-Role-of-Yeast-Beta-Glucan-on-Blood-Coagulation-El-KashouryFattah/6f68a9067831eebb0015c2961882d1e91a89e84f . Accessed, June 18, 2020.

51. Williams DL, Mueller A, Browder W. Glucan-Based Macrophage Stimulators. Clin Immunother. 5:392-9. https://doi.org/10.1007/BF03259335.

52. Babineau TJ, Marcello P, Swails W, Kenler A, Bistrian B, Forse RA Randomized phase I/II trial of a macrophage-specific immunomodulator (PGG-glucan) in high-risk surgical patients. Ann Surg. 1994;220:601-9.

53. Sissener EC, Engstad RE, Olsen JO, Østerud B. The effect of soluble h-1, 3glucan and lipopolysaccharide on cytokine production and coagulation activation in whole blood. Int Immunopharmacol. 2002:2:1585-97.
54. Ikewaki N, Fujii N, Onaka T, Ikewaki S, Inoko H. Immunological actions of Sophy beta-glucan (beta-1,3-1,6 glucan), currently available commercially as a health food supplement. Microbiol Immunol. 2007;51:861-73.

55. Yatawara L, Wickramasinghe S, Nagataki M, et al. Aureobasidium-derived soluble branched (1,3-1,6) beta-glucan (Sophy beta-glucan) enhances natural killer activity in Leishmania amazonensis-infected mice. Korean J Parasitol. 2009;47:345-51.

56. Muramatsu D, Iwai A, Aoki $S$, et al. $\beta$-Glucan derived from Aureobasidium pullulans is effective for the prevention of influenza in mice. PLoS One. 2012;7:e41399.

57. Henry BM, Vikse J, Benoit S, Favaloro EJ, Lippi G. Hyperinflammation and derangement of renin-angiotensin-aldosterone system in COVID-19: a novel hypothesis for clinically suspected hypercoagulopathy and microvascular immunothrombosis. Clin Chim Acta. 2020;507:167-73.

58. Dedeepiya VD, Sivaraman G, Venkatesh AP, Preethy S, Abraham SJ. Potential effects of nichi glucan as a food supplement for diabetes mellitus and hyperlipidemia: preliminary findings from the study on three patients from India. Case Rep Med. 2012;2012:895370.

59. Ganesh JS, Rao YY, Ravikumar R, et al. Beneficial effects of black yeast derived 1-3, 1-6 Beta Glucan-Nichi Glucan in a dyslipidemic individual of Indian origin--a case report. J Diet Suppl. 2014;11:1-6.

60. Ikewaki N. Results of oral consumption of AFO-202 Beta Glucan in elderly volunteers and cancer patients through NK cell activity. Abstract presented at 28th Annual Meeting of Japanese Society for Parenteral and Enteral Nutrition; 2013.

61. Pretorius L, Thomson GJA, Adams RCM, Nell TA, Laubscher WA, Pretorius E. Platelet activity and hypercoagulation in type 2 diabetes. Cardiovasc Diabetol. 2018;17:141.

\section{Publisher's Note}

Springer Nature remains neutral with regard to jurisdictional claims in published maps and institutional affiliations.

Ready to submit your research? Choose BMC and benefit from:

- fast, convenient online submission

- thorough peer review by experienced researchers in your field

- rapid publication on acceptance

- support for research data, including large and complex data types

- gold Open Access which fosters wider collaboration and increased citations

- maximum visibility for your research: over $100 \mathrm{M}$ website views per year

At BMC, research is always in progress.

Learn more biomedcentral.com/submissions 